\title{
AC 2012-4521: MOBILE STUDIO PEDAGOGY, PART 2: SELF-REGULATED LEARNING AND BLENDED TECHNOLOGY INSTRUCTION
}

Prof. Kenneth A Connor, Rensselaer Polytechnic Institute

Kenneth Connor is a professor in the Department of Electrical, Computer, and Systems Engineering where he teaches courses on plasma physics, electromagnetics, electronics and instrumentation, electric power, and general engineering. His research involves plasma physics, electromagnetics, photonics, engineering education, diversity in the engineering workforce, and technology enhanced learning. Since joining the Rensselaer faculty in 1974, he has been continuously involved in research programs at such places as Oak Ridge National Laboratory and the Universities of Texas and Wisconsin in the U.S., Kyoto, and Nagoya Universities in Japan, the Ioffe Institute in Russia and Kharkov Institute of Physics and Technology in Ukraine. He was ECSE Department Head from 2001-2008 and served on the board of the ECE Department Heads Association from 2003-2008. He is presently the Director of Education for the SMART LIGHTING NSF ERC.

Dr. Dianna L. Newman, University at Albany/SUNY

Mrs. Meghan Morris Deyoe, University at Albany/SUNY 


\title{
Mobile Studio Pedagogy Part 2: Self-Regulated Learning and Blended Technology Instruction
}

\begin{abstract}
This paper presents findings from a series of experiments underway in an electronics class for engineering students in which several approaches are currently being implemented to promote self-regulated learning using mobile studio pedagogy. An overview of the project is provided, followed by the presentation of students' self-reported data collected on learning outcomes. Data indicate of the four approaches to learning used, students who used a deep learning approach (overall and autonomously) had greater gains in course content and content specific outcomes. Students who participated in the deep learning-all modalities group (which included autonomous and peer practice in class, lab, and via homework) had the greatest gains in general learning and transfer skills. Deep learning that included only peer collaboration did not appear to be any more successful than traditional surface learning.
\end{abstract}

\section{INTRODUCTION}

Hands-on exploration of STEM (Science, Technology, Engineering and Mathematics) education principles, devices, and systems has historically been restricted to expensive, limited access classrooms; student interaction with resources, materials, and tools are limited by time, instructor, and institutional policies and infrastructure. Although students may learn the "facts" and how to duplicate processes, there is little support for rehearsal of knowledge, development of connected learning, or generation of new knowledge. Learning under this approach is further hampered by frequent lack of continuity between content and practice presented in lecture, lab, and homework. One method used to counter this surface learning (e.g., lack of connectivity and student generated knowledge) and move students to deep learning (e.g., direct application, embedded practice, and constructionist based analysis and synthesis) is the use of a studio approach to learning. In the studio approach to instruction, the invisible walls between the lecture hall and the lab are broken down, and students blend lecture and laboratory activities at the same site using interactive, collaborative modes. ${ }^{1,2}$ The ability to immediately rehearse what has been taught, to practice until familiar with concepts, and to expand and transfer knowledge via instructor guided questions and self-exploration has been shown to be highly successful. ${ }^{3}$ Students learn more, retain more, and are more motivated to continue learning. Despite these positive outcomes, many institutions are still loath to implement the approach due to the cost of creating the required infrastructure - the combined classroom and lab represented by a studio classroom. In an effort to overcome this barrier, several institutions, including Rensselaer Polytechnic Institute (RPI) have developed a mobile approach to the studio classroom. This mobile studio pedagogy makes use of small, inexpensive hardware platforms developed for use in a home, classroom or remote environment. The purpose of these devices is to enable immediate localized hands-on exploration of STEM education principles, devices, and systems that have historically been restricted to expensive laboratory facilities. ${ }^{\mathrm{a}}$

\footnotetext{
${ }^{a}$ Hardware/software platforms are now readily available from a variety of sources including RPI’s Mobile Studio I/O Board and similar products developed by National Instruments ${ }^{\circledR}$ and Digilent ${ }^{\circledR}$.
} 
Notable among these is the Mobile Studio learning platform developed at RPI. ${ }^{\mathrm{b}}$ A typical experimental configuration for a mobile studio based activity is shown below. The laptop, USB cable and Mobile Studio I/O board and Desktop Software provide the necessary measurement capabilities usually provided by an oscilloscope, a computer interface, (e.g., GPIB) and a computer to store and analyze the data. ${ }^{4,5}$ Using this configuration, the Mobile Studio Desktop Software can save data to a file format compatible with the use of spreadsheets or other analysis tools. In the example shown, the experiment is a very simple optical communications system in which an audio signal (e.g. a wav file containing a spoken phrase from a popular film) is used to modulate the light output of a high brightness white or blue LED. The signal is detected by a solar cell. Both the original and detected signals are shown on the Mobile Studio oscilloscope. This setup is used both for outreach and in an undergraduate electronics course taken by students outside of electrical engineering. A more complete discussion of the use of Mobile Studio software and hardware is found in Mobile Studio Pedagogy, Part 1 in this conference.

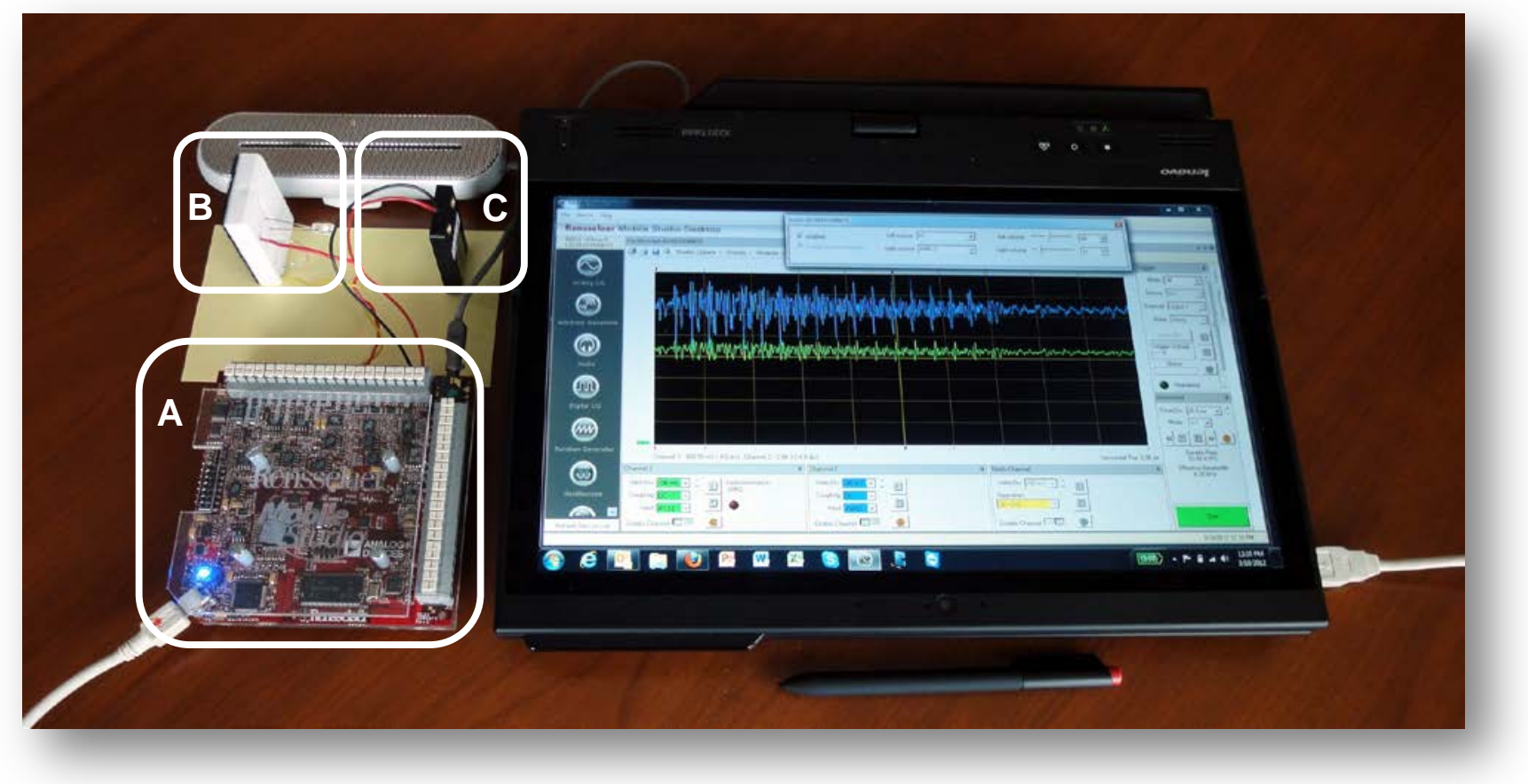

Example of Mobile Studio Experimental Setup for a free space optical communications system: (A) Mobile Studio Board, (B) Transmitter (C) Receiver. Not labeled are the external speaker driven by the Mobile Studio audio amplifier, the laptop computer, and the USB cable.

When using a mobile studio approach, instructors are able to offer a rich blend of technologies through which students learn by conducting experiments, running simulations (e.g. using some version of SPICE), solving traditional paper and pencil problems, watching video lectures, reading online background materials, etc. anywhere and anytime. Blended learning theory indicates that to be successful in this enhanced environment, key instructional characteristics that support learning must be present - these include not only frequent use and availability of resources but also scaffolded opportunities to practice in multiple modalities and the presence of

\footnotetext{
${ }^{\mathrm{b}}$ The Mobile Studio platform and supporting materials originated at RPI with support from National Science Foundation (NSF) Course Curriculum and Laboratory Improvement (CCLI) projects with subsequent refinement at Howard University and Rose-Hulman Institute of Technology
} 
instructor support and encouragement for constructionist learning. ${ }^{6}$ This paper presents findings from a series of experiments underway in an electronics class for engineering students in which several approaches are currently being implemented to promote self-regulated learning. Instructors varied the role, frequency and status of these key characteristics to determine which might have the most impact on student learning.

\section{THEORETICAL BACKGROUND}

Learning theory suggests that an effective way of obtaining and retaining new concepts and skills can be structured around the use of constructionist, and more specifically, constructivist principles. ${ }^{7,8}$ Under these approaches, students experience new areas of knowledge within a scaffolded environment guided by the instructor. This allows the learner to relate new concepts to what they already understand, and to 'play' with new ideas using trial and error to develop understanding. This approach is supported by empirical literature which demonstrates that to obtain competence, proficiency, or expertise in a domain it is necessary for the learner to practice until a level of familiarity, and ideally automaticity, in basic skills is reached. ${ }^{9-12}$ Additional literature suggests that learning in collaborative settings, in and out of the classroom, increases how much students retain and their subsequent ability to move facts to practice and their ability to solve real-life problems relevant to their interests. ${ }^{13}$ Each of these successes enhances learners' perceptions of self-competence, content self-efficacy, and motivation to learn more.

Educational research has expanded the concept of scaffolding to encompass "surface" and "deep" learning as part of instructional design and development. ${ }^{14,15}$ A consistent finding among the research studies is that higher quantity and quality of learning outcomes are related to the presence of deeper supports for learning and instruction. ${ }^{16}$ When the instructional method includes self-directed learning, group discussion and reflection to promote and/or challenge idea, students were more likely to adopt a deep approach to learning, to take responsibility for determining their learning goals, and to self-monitor their progress, ${ }^{17}$ as well as self-generate active experimentation and problem-based learning. ${ }^{18}$ The presence of these variables is not enough. The role of the instructor is very important; in student-directed instruction if successful deep learning is to occur; the instructor must be present and actively supportive of students' engagement in hand-on practice and self-generated knowledge. ${ }^{19}$ Students' perception of the instructor's value of the process, what the instructor conveys to the student in terms of what is expected of them as learners, and what activities the instructor conveys as important (e.g., rote learning, rehearsal, replication practice or generativity) is reflected in students' self-reported learning expectations and outcomes. ${ }^{20}$ Students' perceived importance of real world practice is based on the importance of practices as relayed by their faculty and, subsequently, is positively related to higher levels of learning outcomes. ${ }^{21,22}$ Based on this research, it is important to investigate the effects of these variables on the process of implementing a mobile studio classroom, on students' perceptions of the learning environment in mobile studio settings, and on students’ learning outcomes.

\section{METHODS}

Participants in this study represented engineering students enrolled in an electronics course at a private institute of higher education. The sample was comprised of engineering students $(\mathrm{n}=187)$ 
from electronics courses in which a self-regulated learning environment was promoted through use of the Mobile Studio; in the most in depth approach, students were conducting experiments, running simulations, solving traditional paper and pencil problems, watching video lectures, and reading online background materials. All major concepts were presented in the context of the engineering design process so that the students could see each new system addressed as an example of how engineers typically do their jobs. Every new idea was then

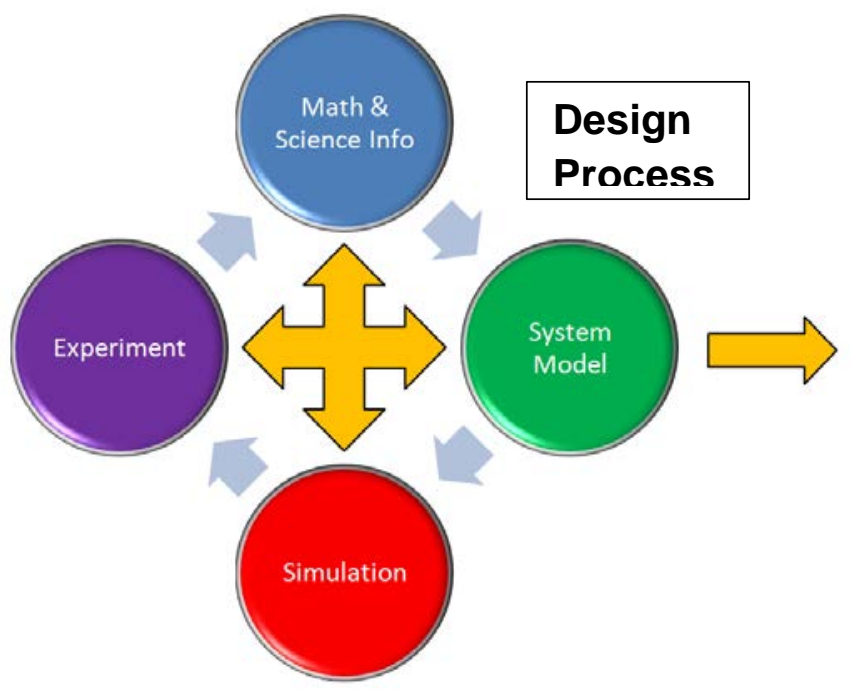
presented three times (from fundamental simplified theory, from simulation, and from experimentation) and students were asked to develop a practical system model that would permit them to design other systems for specific applications. Students in this approach worked in teams whose members self-assigned responsibilities for each activity (experiments and design projects) and the instructor and teaching assistants checked on the preparation and performance through a task checklist completed for each activity. Assessment of the success was based on the final system model that students developed. As part of this process, students also were asked to document at the end of the course, their perceptions of instructional support and outcomes related to content and affective learning outcomes.

\section{RESULTS}

A one-way analysis of variance was used to analyze student learning outcomes; the grouping variable represented four different levels of support for blended self-regulated learning. Multiple dependent constructs related to student learning and student affective outcomes were examined. Content specific learning outcomes represented knowledge specifically related to the course. Outcomes reflecting a positive learning affect included two sub-constructs: items related to the specific course (e.g., confident and interest in the specific content) and those related to general learning (e.g., increased general motivation to learn within the discipline and developing a sense of self learning). Outcomes reflecting future learning also included two sub-constructs: items related to skills needed for future learning (e.g., the ability to solve problems, transfer knowledge and work collaboratively) and items related to learning affects needed to support future learning (e.g., self-confidence about ability to do future work in engineering, future homework, and communication of ideas). Summaries of the means and standard deviations for each category of learning outcomes and associated ANOVA results are presented in Tables 1-3.

\section{4.a. Levels Of Support For Blended Self-Regulated Learning}

Four levels of support for blended learning were identified through a cluster analysis of student reported perceptions of faculty involvement, frequency and levels of use, areas of practice, and purpose of learning. Following is summary of each level: 
- Deep learning — practice in all modalities was defined as an approach to learning facilitated by the frequent use of the Mobile Studio in class, lab, and for homework that encouraged both in-group and autonomous practice in all three settings. In addition, students reported instructional support and adequate time for practice/use. This is the group that received all forms and approaches.

- Deep learning - autonomous practice was defined as an approach to learning for students facilitated by occasional use of the Mobile Studio, in class and lab but not for homework, that encouraged autonomous or individual practice. In addition, students reported instructional support and adequate time for practice/use. These students were not actively involved in the self-regulating learning groups.

- Deep learning - collaborative practice was defined as an approach to learning for students facilitated by occasional use of the Mobile Studio, in class and lab but not for homework, that encouraged collaborative group work. In addition students reported instructional support and adequate practice time. These students were actively involved in learning groups, but had little opportunity to practice "solo."

- Surface learning was defined as an approach to learning for students who reported rarely using the Mobile Studio for in-class, lab, or for homework purposes, and consequently received no encouragement for either autonomous or collaborative practice. In addition, these students reported very limited instructional support and perceived very little time for practice/use. This group of students serve as the control or master comparison group; they received limited if any mobile studio instruction and no blended self-regulation activities.

\section{4.b. Course Specific Outcomes}

Significant differences by type of blended self-regulation support were found for all variables representing course specific outcomes. Overall, all four groups "agreed" that use of the Mobile Studio I/O boards helped in content-related learning no matter what type of support was provided for blended self-regulated learning. (See Table 1 for means and standard deviations; shaded boxes represent the highest rating.) Of the four groups, however, students in the deep learningautonomous group reported the greatest impact on specific content outcomes while students in the deep learning collaborative group tended to report few learning outcomes. More specifically, those students who learned and practiced alone during both class and lab, even with no rehearsal via homework but who did perceive high instructor support, reported that their course-related knowledge had increased and that their work reflected the real world and real practices. On the other hand, students in the deep learning — collaborative group who experienced a similar support system except of the use of a collaborative learning modality (instead of autonomous learning) reported lower gains. This was especially true for items related to recall of knowledge via pictorial and graphical methods as well as general knowledge. Use of both peer and autonomous learning, including use via homework, (i.e., deep learning — all forms) did not appear to markedly impact indicators of specific course content. Overall, the surface learning group reported fewer positive impacts than any other group, but was most similar in ratings with the deep learning — collaborative group. 
Table 1

Means and Standard Deviations of Student Learning Approaches on Specific Content Learning Outcomes

\begin{tabular}{|c|c|c|c|c|c|c|c|c|c|}
\hline \multirow{3}{*}{ Specific Content Learning Outcomes } & \multirow{2}{*}{\multicolumn{2}{|c|}{$\begin{array}{c}\text { Deep } \\
\text { Learning- } \\
\text { All Forms } \\
n=39 \\
\end{array}$}} & \multirow{2}{*}{\multicolumn{2}{|c|}{$\begin{array}{c}\text { Deep } \\
\text { Learning- } \\
\text { Autonomous } \\
n=83 \\
\end{array}$}} & \multirow{2}{*}{\multicolumn{2}{|c|}{$\begin{array}{c}\text { Deep } \\
\text { Learning- } \\
\text { Collaborative } \\
n=52\end{array}$}} & \multirow{2}{*}{\multicolumn{2}{|c|}{$\begin{array}{c}\begin{array}{c}\text { Surface } \\
\text { Learning }\end{array} \\
n=13 \\
\end{array}$}} & \multirow{3}{*}{$\begin{array}{c}\text { Significant } \\
\text { ANOVA } \\
\mathbf{p}<.01 \\
* *\end{array}$} \\
\hline & & & & & & & & & \\
\hline & $\overline{\bar{x}} *$ & sd & $\bar{x} *$ & $s d$ & $* \bar{x}$ & $s d$ & $* \bar{x}$ & sd & \\
\hline $\begin{array}{l}\text { Knowledge increased after taking the } \\
\text { course }\end{array}$ & 5.13 & 0.83 & 5.53 & 0.69 & 4.58 & 1.05 & 4.54 & 1.20 & yes \\
\hline Reflected course content & 5.18 & 0.79 & 5.66 & 0.55 & 4.87 & 0.74 & 5.00 & 0.82 & yes \\
\hline Reflected real practice & 5.00 & 0.86 & 5.22 & 0.84 & 4.27 & 0.93 & 4.85 & 0.80 & yes \\
\hline $\begin{array}{l}\text { Helped students think } \\
\text { graphical/pictorial or practical ways }\end{array}$ & 4.72 & 0.92 & 4.89 & 0.88 & 4.25 & 1.10 & 4.08 & 1.19 & yes \\
\hline Helped students recall course content & 4.54 & 0.76 & 4.70 & 0.86 & 3.87 & 1.09 & 4.08 & 1.32 & yes \\
\hline
\end{tabular}

*mean ratings based on a six point Likert-type scale (1=Strongly Disagree, $6=$ Strongly Agree)

** Analysis of Variance significant at an alpha level of $p<.01$

\section{4.c. Outcomes Reflecting A Positive Learning Affect}

Outcomes reflecting a positive learning affect included two sub-constructs: items related to the specific course and those related to general learning. (See Table 2 for a summary of responses; shaded values indicate highest response.) Overall students rated themselves as lower in these areas than in the previous content knowledge outcomes. In addition, greater variation in responses was noted; while some students strongly agreed that the method in which they participated assisted them, others only slightly agreed. These variations are related to type of blended self-regulated learning and are consistent within the two sub-constructs of course specific affect and general learning affect. When examining items for the sub-construct course specific affect, it was found that students who adopted a deep learning-autonomous approach reported higher confidence and interest in course content area than did any other group. Similar to the course/content specific knowledge outcomes noted in the previous section, these results are similar to those found for the deep learning - all forms group. The surface learning group again tended to have the lowest rates on specific course related indicators and were similar to those of the deep learning - collaborative group. That is, those students who perceived that they received little or no practice or instructor support, or who worked in collaborative settings using self-regulated learning with instructor support, did not report as great a gain in confidence or interest in the course specific content as those who had opportunities to work alone within the self-regulated approach.

A different pattern was found, however, for the gains related to general learning. For the subconstruct Positive learning affect related to general learning, students in the deep learning-all forms group indicated higher gains in motivation, self-direction and responsibility, and improved grades; that is, students who had used the resources in class, lab and for homework and who worked in groups as well as alone reported greater affect toward learning beyond the specific content. Students in the deep learning-autonomous group, who did not have access for homework but did get to practice by themselves frequently during class and lab, still reported 
positive gains but to a lesser degree. Students in the deep learning-collaborative group and in the surface learning group did not report positive gains in affect needed to support general learning. Both of these groups disagreed that they had improved on all items; there were no major differences by item between these two sets of students.

Table 2

Means and Standard Deviations of Student Learning Approaches on Current Affective Learning Outcomes

\begin{tabular}{|c|c|c|c|c|c|c|c|c|c|}
\hline \multirow{3}{*}{$\begin{array}{l}\text { Current Affective Learning } \\
\text { Outcomes }\end{array}$} & \multirow{2}{*}{\multicolumn{2}{|c|}{$\begin{array}{c}\text { Deep } \\
\text { Learning-- } \\
\text { All Forms } \\
n=39 \\
\end{array}$}} & \multirow{2}{*}{\multicolumn{2}{|c|}{$\begin{array}{c}\text { Deep } \\
\text { Learning- } \\
\text { Autonomous } \\
n=83\end{array}$}} & \multirow{2}{*}{\multicolumn{2}{|c|}{$\begin{array}{c}\begin{array}{c}\text { Deep } \\
\text { Learning- } \\
\text { Collaborative }\end{array} \\
n=52\end{array}$}} & \multirow{2}{*}{\multicolumn{2}{|c|}{$\begin{array}{c}\text { Surface } \\
\text { Learning } \\
n=13 \\
\end{array}$}} & \multirow{3}{*}{$\begin{array}{c}\text { Significant } \\
\text { ANOVA } \\
\mathbf{p}<.01 \\
* *\end{array}$} \\
\hline & & & & & & & & & \\
\hline & $\bar{x} *$ & $s d$ & $\bar{x} *$ & $s d$ & $\bar{x} *$ & sd & $\bar{x} *$ & sd & \\
\hline \multicolumn{10}{|c|}{ Outcomes reflecting a positive learning affect related to course specific content } \\
\hline Developed confidence in content area & 4.79 & 0.80 & 4.99 & 0.74 & 4.12 & 1.06 & 4.46 & 0.88 & Yes \\
\hline Developed interest in content area & 4.37 & 1.08 & 4.61 & 0.94 & 3.80 & 1.20 & 3.92 & 1.66 & Yes \\
\hline $\begin{array}{l}\text { Increased confidence in content area } \\
\text { knowledge }\end{array}$ & 4.76 & 1.08 & 5.01 & 0.77 & 3.96 & 1.01 & 4.08 & 1.61 & Yes \\
\hline \multicolumn{10}{|c|}{ Outcomes reflecting a positive learning affect related to general learning outcomes } \\
\hline Become motivated to learn content & 4.36 & 1.04 & 4.22 & 1.13 & 3.48 & 1.23 & 3.54 & 1.51 & Yes \\
\hline Developed self-direction/ responsibility & 4.74 & 0.94 & 4.30 & 1.11 & 3.71 & 1.07 & 3.92 & 1.32 & Yes \\
\hline Helped improve grades & 4.59 & 1.14 & 4.29 & 1.18 & 3.67 & 1.34 & 3.54 & 1.51 & Yes \\
\hline
\end{tabular}

*mean ratings based on a six point Likert-type scale (1=Strongly Disagree, 6=Strongly Agree)

** Analysis of Variance significant at an alpha level of $p<.01$

\section{4.d. Outcome Related to Future Learning}

Outcomes reflecting future learning also included two sub-constructs: items related to skills needed for future learning and items related to learning affects needed to support future learning. Overall responses to items reflecting skills needed for future learning tended to reflect the same level of attainment as items reflecting current course affect-students tended to agree that they had obtained these skills but to a lesser degree than they had obtained specific course content knowledge. Responses continued to vary by degree of blended self-regulated support provided via a mobile studio approach. For this construct, student who participated in the deep learningall forms activities reported higher attainment than did any other group. That is, those students who had access to the mobile studio pedagogy in class, lab, and through homework and who practiced both alone and together with peers reported that they were better able to work collaboratively, transfer knowledge to problems and settings, and had greater skills in problem solving within the content area than did students who had some of these opportunities but not all of them. Students in the deep learning-autonomous setting reported the second ranked degree of attainment; students in the remaining two groups, deep learning collaboration and surface learning reported markedly lower responses on attainment of skills needed for advanced work. This pattern follows that reported by students when queried about general learning outcomes- 
students who had more opportunity to practice, and in all three formats, with peers and alone, reported having the affect and the skills needed for both general and future learning.

Responses to one item within this domain are of special note-significant differences were found between groups when queried about having a skill in problem solving in the content area but no differences were found between groups when queried about the attainment of different ways to solve problems. In addition, responses reflecting a specific problem solving ability were higher than responses reflecting a repertoire of skills. Overall, students were less certain of their ability to solve problems in different ways than they were in one particular way within a specific content area. While not significantly different, it was noted that the group with the highest confidence in using different methods were members of the deep learning — all forms mode of instruction.

Overall responses to items reflecting affect needed to support future learning showed negative results. Across all groups, students indicated that they had not gained in this domain (all means less than a 3.0), and no difference between instructional methods was found between groups on any of the explicit indicators except for the ability to communicate with peers. Examination of the responses indicated that students, across all types of support, perceived that they were lacking in the ability to do advanced coursework, to complete future homework, and to be successful in engineering. Overall, all students also reported limited ability to communicate ideas with their classmates. Examination of group means, while not significant, indicate that support for blended self-regulated learning did not assist in gaining these affective supports for future learning; in fact, students in the surface learning group had a higher, though still negative, perception of their ability than did the other groups.

\section{Table 3}

\section{Means and Standard Deviations of Student Learning Approaches on Future Transfer/Affective Learning Outcomes}

\begin{tabular}{|c|c|c|c|c|c|c|c|c|c|}
\hline \multirow[t]{3}{*}{ Future Learning } & \multirow{2}{*}{\multicolumn{2}{|c|}{$\begin{array}{c}\begin{array}{c}\text { Deep } \\
\text { Learning-- } \\
\text { All Forms }\end{array} \\
n=39\end{array}$}} & \multirow{2}{*}{\multicolumn{2}{|c|}{$\begin{array}{c}\begin{array}{c}\text { Deep } \\
\text { Learning- } \\
\text { Autonomous }\end{array} \\
n=83 \\
\end{array}$}} & \multirow{2}{*}{\multicolumn{2}{|c|}{$\begin{array}{c}\text { Deep } \\
\begin{array}{c}\text { Learning- } \\
\text { Collaborative }\end{array} \\
n=52 \\
\end{array}$}} & \multirow{2}{*}{\multicolumn{2}{|c|}{$\begin{array}{c}\begin{array}{c}\text { Surface } \\
\text { Learning }\end{array} \\
n=13 \\
\end{array}$}} & \multirow{3}{*}{$\begin{array}{c}\text { Significa } \\
\text { nt } \\
\text { ANOVA } \\
\mathbf{p}<.01 \\
* *\end{array}$} \\
\hline & & & & & & & & & \\
\hline & $\overline{\bar{x}} *$ & sd & $\bar{x} *$ & sd & $\overline{\bar{x}} *$ & sd & $\overline{\bar{x}} *$ & sd & \\
\hline \multicolumn{10}{|c|}{ Outcomes reflecting skills needed for future learning } \\
\hline Work collaboratively & 5.18 & 0.85 & 5.06 & 0.93 & 4.69 & 1.04 & 4.38 & 1.04 & yes \\
\hline Develop different ways to solve problems & 4.44 & 0.88 & 4.22 & 1.25 & 3.71 & 1.07 & 4.23 & 1.36 & no \\
\hline $\begin{array}{l}\text { Transfer knowledge/skills to outside } \\
\text { problems }\end{array}$ & 4.54 & 1.07 & 4.30 & 1.07 & 3.58 & 1.21 & 4.00 & 1.53 & yes \\
\hline Apply course content to new problems? & 4.69 & 0.83 & 4.59 & 0.88 & 4.00 & 1.12 & 4.08 & 1.32 & yes \\
\hline Skill in problem solving in content area & 4.72 & 0.83 & 4.56 & 1.06 & 3.98 & 1.16 & 4.08 & 1.38 & yes \\
\hline \multicolumn{10}{|c|}{ Outcomes reflecting affective support needed for future learning } \\
\hline $\begin{array}{l}\text { Ability to communicate ideas with } \\
\text { classmates }\end{array}$ & 2.00 & 0.94 & 1.98 & 0.82 & 2.48 & 0.94 & 2.62 & 1.45 & yes \\
\hline Belief can do advanced work in engineering & 2.03 & 0.97 & 2.09 & 0.98 & 2.27 & 1.17 & 2.31 & 1.49 & no \\
\hline Self-confidence about engineering & 2.33 & 1.13 & 2.41 & 1.03 & 2.65 & 1.12 & 2.69 & 1.25 & no \\
\hline $\begin{array}{l}\text { Confidence in completing engineering } \\
\text { homework }\end{array}$ & 2.28 & 0.89 & 2.21 & 1.07 & 2.46 & 1.04 & 2.62 & 1.39 & no \\
\hline
\end{tabular}

*mean ratings based on a six point Likert-type scale (1=Strongly Disagree, 6=Strongly Agree)

** Analysis of Variance significant at an alpha level of $p<.01$ 


\section{CONCLUSIONS}

Findings from this study indicate that students who received the deep learning—all forms or deep learning - autonomous approach to mobile studio pedagogy had the instructional support and practice time necessary to develop the skills related to learning the course content, which subsequently may have facilitated their affective learning. These students, all of whom used the Mobile Studio independently for practice, had more time and opportunity to work on problems and apply the course content; thus, benefitting their content learning for the course. Students who participated in a deep learning - collaborative approach or a surface learning approach had lower gains, especially in affective categories of confidence and motivation. These findings suggest that students who frequently used the Mobile Studio with strong instructional support and greater practice time tended to progress in both content and affective domains quicker than did students who either rarely used the board and/or had moderate to limited amounts of instruction or independent practice time. Students who used deep learning-all forms as their main approach reported the greatest ability to transfer learning outcomes related to the development and application of skills in the content area to outside problems and collaborative learning. These student had the most practice, both autonomous and with peers in class, in the lab, and through homework. Students who had either the deep learning — all forms or deep learning - autonomous approach tended gain in the development of skills that could be transferred in other areas. The overall low ratings on most items related to the presence of affect needed to support future learning, including self-confidence and belief that one can be successful, suggests that further research should be conducted to determine the reasons for this low perception.

Acknowledgment: This work was supported primarily by the Engineering Research Centers Program of the National Science Foundation under NSF Cooperative Agreement EEC-0812056 and the NSF Division of Undergraduate Education under DUE-0717832.

\section{References}

1. Grant, M. M. (2002). "Getting a grip on project-based learning: Theory, cases and recommendations.” Meridian: A Middle School Computer Technologies Journal, 5.

2. Newman, D., Reinhard, D.E., Clure, G. (2007). "Using constructivist methods in technology supported learning: Evidence of student impact.” University at Albany/SUNY. Paper presented at the American Educational Research Association, Chicago Illinois.

3. D. Newman, G. Clure, M. Morris Deyoe, K. Murphy, \& K. Connor (2011, April). "Moving the Lab to the Classroom: The Effects of Laptop Supported Technology on Learning," Presented at the American Education Research Association Conference, New Orleans, LA.

4. K. Connor, C. Scott, M. Chouikha, A. Wilson, A. Anderson, Y. Astatke, F. Berry, D. Newman, J. O’Rourke, T. Little, D. Millard. (2011) "Multi-Institutional Development of Mobile Studio Based Education and Outreach,” ASEE Annual Conference, Vancouver, BC, June 2011 AC2011-2039.

5. K. Connor, F. Berry, M. Chouikha, D. Newman, M. Deyoe, G. Anaya, W. Brubaker. (2011) "Using the Mobile Studio to Facilitate Non-Traditional Approaches to Education and Outreach,” ASEE Annual Conference, Vancouver, BC, June 2011 AC2011-2250.

6. D. R. Garrison \& H. Kanuka (2004). "Blended learning: Uncovering its transformative potential in higher education." The Internet and Higher Education, 7 (2): 95-105. 
7. J. Piaget \& B. Inhelder (1955), "Growth of logical thinking.” London: Routledge \& Kegan Paul, 1958.

8. L.S. Vygotsky. (1978). "Mind in Society: The development of higher psychological processes." Cambridge, MA: Harvard University Press.

9. B. Abernethy. (1993). Searching for the minimum essential information for skilled perception and action. Psychological research, 55, 131-138.

10. E.R.. Guthrie. (1952). The Psychology of Learning: Revised Edition. Harper Bros:Massachusetts.

11. E. Kim, J. Kim, \& S. Hong. (2007). The effects of students' intrinsic motivation on academic achievement and preference for cooperative learning" Paper presented at the annual meeting of the International Communication Association, San Francisco, CA.

12. S.H. Boutcher. (1992). Attention and athletic performance: an integrated approach. In: Horn, T.S., Editor, Advances in sport psychology, human kinetics, Champaign, IL, pp. 251-265.

13. N. Klingbeil, K. Rattan, M. Raymar, D. Reynolds \& R. Mercer. (2007). The Wright State model for engineering mathematics education: Increasing student retention, motivation and success in engineering. Retrieved September 19, 2009, from http://www.engineering.wright.edu/cecs/engmath/presentations/WSU_Eng_Math_08.pdf

14. N.J. Entwistle. (1991). Approaches to learning and perceptions of the learning environment: introduction to the special issue. Higher Education, 22, 201-204.

15. F. Marton \& Saljo. (1976). On qualitative differences in learning - 1: outcome and Process. British Journal of Educational Psychology, 46, 4-11.

16. K. Trigwell \& M. Prosser. (1997). Towards an understanding of individual acts of teaching and learning. Higher Education Research and Development, 16, 241-252.

17. M.J. Hannafin, K.M. Hannafin, \& B. Gabbitas. (2009). Re-examining cognition during student-centered, web-based learning. Educational Technology Research and Development, 57 (6), 767-785.

18. L.R. de Camargo Ribeiro. (2008). Electrical engineering students evaluate problem-based learning (PBL). International Journal of Electrical Engineering Education, 45 (2), 152-161.

19. S. Malik \& M.S. Shabbir. (2008). Perception of university students on self-directed learning through learning technology. European Journal of Scientific Research, 24 (4), 567-574.

20. M. Delucchi. (2000). Don't worry, be happy: instructor likability, student perceptions of learning and teacher rating in upper-level sociology courses. Teaching Sociology, 28 (3), 220-231.

21. S. Drew. (2001). Student perceptions of what helps them learn and develop in higher education. Teaching in Higher Education, 6 (3), 209-331.

22. T. Cronje \& R.K. Coll. (2008). Student perceptions of higher education science and engineering learning communities. Research in Science \& Technological Education, 26 (3), 295-309. 